UDC 54.057

Author: SHAPOVALOV Nikolay Afanasyevich, Professor, Doctor of Engineering, First Vice-Rector of Belgorod State technological University named after V.G. Shoukhov; Kostyukov str., 46, Belgorod, Russia, 308012,val.po@bk.ru;

Author: POLUEKTOVA Valentina Anatolyevna, Ph.D. in Engineering, Associate Professor, Associate Professor of the Department of Pure and Applied Chemistry, Belgorod State technological University named after V.G. Shoukhov; Kostyukov str., 46, Belgorod, Russia, 308012, v.a.poluektova@gmail.com

\title{
FEATURES OF NANOMODIFIERS SYNTHESIS BASED ON TRIFUNCTIONAL OXYPHENYLS FOR MINERAL SUSPENSIONS
}

\section{Extended Abstract:}

The focused influence on the rheological characteristics of highly-concentrated mineral suspensions used in the building industry is possible due to the directed synthesis of nano-sized macromolecules that have the certain structure and high adsorbing capacity on the surface of mineral particles and that are able to modify the boundary layer composition. The adsorbing capacity of organic compounds depends mostly on the hydrocarbon chain length and the molecular weight of the compound.

The result of the condensate interaction of phenol and its derivatives with aldehydes is oligomers and polymers whose structure depends on the phenol functionality, the kind of aldehyde, molecular ration of reagents, the $\mathrm{Ph}$ medium of the reaction. So, changing the type or the functionality of initial monomers or the synthesis conditions one can produce linear thermoplastic oligomers (novolacs) or highly branched thermosetting oligomers (resols). It has been found that the resole production takes place under softer conditions, and there is no necessity to neutralize reaction products as with novolac production that usually requires acid environment.

A number of thermosetting oligomers based on trifunctional polyatomic phenols have been synthesized. The theoretical and practical characteristics of resole oligomer synthesis have been studied, synthesis optimal conditions have been determined, the composition and structure of macromolecules were revealed by the methods of infrared spectroscopy, proton magnetic resonance spectroscopy, liquid chromatography and conductivity measurement, the length of the enlarged oligomer molecule was calculated. Obtained compounds can be qualified as nanoscaled modifiers of mineral dispersions.

Key words: nanomodifier, trifunctional phenols, synthesis of macromolecules, plasticizing ability.

DOI: dx.doi.org/10.15828/2075-8545-2016-8-5-100-115

http://nanobuild.ru 
MACHINE-READABLE INFORMATION ON CC-LICENSES (HTML-CODE) IN METADATA OF THE PAPER

$<$ a rel="license" href="http://creativecommons.org/licenses/by/4.0/" ><img alt="Creative Commons License" style="borderwidth:0" src="https://i.creativecommons.org/l/by/4.0/88x31.png" $/></ \mathrm{a}><$ br $/><$ span xmlns:dct="http://purl.org/dc/ terms/" href="http://purl.org/dc/dcmitype/Text" property="dct:title" rel="dct:type" $>$ Features of nanomodifiers synthesis based on trifunctional oxyphenyls for mineralsuspensions $</$ span $>$ by $<$ a xmlns:cc="http://creativecommons.org/ns\#" href="Nanotehnologii v stroitel'stve = Nanotechnologies in Construction. 2016, Vol. 8, no. 5, pp. 100-115. DOI: dx.doi. org /10.15828/2075-8545-2016-8-5-100-115" property="cc:attributionName" rel="cc:attributionURL" >Shapovalov N.A., Poluektova V.A. $</ a>$ is licensed under a $<$ a rel="license" href="http://creativecommons.org/licenses/by/4.0/" $>$ Creative Commons Attribution 4.0 International License $</ \mathrm{a}>$. $<$ br $/>$ Based on a work at $<$ a xmlns:dct="http://purl.org/dc/terms/" href="http://nanobuild.ru/en_EN/nanobuild-5-2016" rel="dct:source" $>$ http://nanobuild.ru/en_EN/nanobuild-5-2016</ $\mathrm{a}>$. $<$ br $/>$ Permissions beyond the scope of this license may be available at $<$ a xmlns:cc="http://creativecommons.org $/ \mathrm{ns} \# "$ href="val.po@bk.ru"rel="cc:morePermissions">val.po@bk.ru</a>.

\section{References:}

1. Lipatov Y.S., Sergeeva L.M. Adsorbcija polimerov [Polymer adsorption]. Kiev: Naukova Dumka, 1972, 196 p. (In Russian)

2. Lipatov Y.S. Sovremennye teorii adsorbcii polimerov na tverdyh poverhnostjah [Modern theories of polymer adsorption on hard surfaces]. Uspekhi chimii [Success of Chemistry] 1981, Vol. 50, № 2, pp. 355-379. (In Russian).

3. Kharitonova T.V., Ivanova T.I., Sushm B.D. Adsorbcija kationnogo i neionogennogo PAV na poverhnosti SiO2 iz vodnyh rastvorov [Adsorption of cationic and nonionic surface active agent on $\mathrm{SiO} 2$ surface from aqueous solutions]. Kolloidnyj zhurnal [Colloid Journal]. 2005, Vol. 67, № 2, pp. 274-280. (In Russian).

4. Poluektova, V.A., Shapovalov N.A., Balyatinskaya L.N. Adsorbcija oksifenolfurfurol'nyh oligomerov na dispersnyh materialah [Adsorption of oxyphenol and furfurol oligomer on disperse materials]. Fundamental'nye issledovanija [Fundamental researches]. 2012, no. 11, part. 6, pp. 1470-1474. (In Russian).

5. Vovk A.I. Analiz vzaimosvjazi stroenija PAV s ih adsorbcionnymi harakteristikami v sisteme cementnyj mineral - voda [Interrelation analysis of surface active agents structure and their adsorption characteristics in the system «concrete mineral - water»]. Kolloidnyj zhurnal [Colloid Journal]. 1997, Vol. 59, № 6, pp. 743746. (In Russian).

6. Dolinnyi A.I. Adsorbcija iz smesi polimerov. Jeffekt molekuljarnoj massy [Adsorption from polymers mixture. Effect of molecular weight]. Kolloidnyj zhurnal [Colloid Journal]. 2006, Vol. 68, № 1, pp. 37-45. (In Russian).

7. Shapovalov N.A. Regulirovanie agregativnoj ustojchivosti mineral'nyh suspenzij oligomernymi aromaticheskimi jelektrolitami [Regulation of aggregate stability of mineral suspensions by oligomer aromatic electrolytes]. Abstract of Doctoral Thesis. Belgorod, 1999, 32 p. (In Russian).

8. Poluektova V.A., Lomachenko V.A., Stolyarova Z.V., Lomachenko V.M., Malinovker V.M. Kolloidno-himicheskie svojstva vodnyh dispersij mela i mramora [Colloid- 
chemical features of aqueous dispersions of chalk and marbel]. Fundamental'nye issledovanija [Fundamental research]. 2014, № 9 (part 6), pp. 1205-1209. (In Russian).

9. Poluektova V.A., Stolyarova Z.V., Lomachenko S.M., Chernikov R.O. Adsorption of domestic wastes-based modifier of resorcinol on the surface of mineral particles. International Scientific Journal. 2015, № 4, pp. 45-46.

10. Poluektova V.A., Shapovalov N.A., Kosukhin M.M., Slusar A.A. Plasticizing Additives For Water Mineral Dispersions On The Basis Of Oxyphenol Oligomers. Advances in Natural and Applied Sciences. 2014, Vol. 8, № 5, pp. 373-379.

11. Slusar A.A., Shapovalov N.A., Poluektova V.A. Regulirovanie reologicheskih svojstv cementnyh smesej i betonov dobavkami na osnove oksifenolfurfurol'nyh oligomerov [Rheological characteristics control of cement mixtures and concrete by additives based on oxyphenolfurfural oligomers]. Stroitel'nye materialy [Construction materials]. 2008, № 7, pp. 42-43. (In Russian).

12. Slyusar A.A., Poluektova V.A., Mukhacheva V.D. Kolloidno-himicheskie aspekty plastifikacii mineral'nyh suspenzij oksifenolfurfurol'nymi oligomerami [Colloidal and chemical aspects of plasticization of mineral suspensions by oxyphenol and furfurol oligomer]. Vestnik BGTU. 2008, № 2, pp. 66-69. (In Russian).

13. Poluektova V.A., Shapovalov N.A. and Gorodov A.I. Modifiers on the base of oxyphenol Chemical Production Waste For The Industrial Mineral Suspensions. International journal of applied engineering research. 2015, Vol. 10, № 21, pp. 4265442657.

14. Poluektova V.A., Slyusar A.A., Shapovalov N.A. Superplastifikator na osnove florogljucinfurfurol'nyh oligomerov dlja vodnyh mineral'nyh suspenzi [Supersoftener on the basis of floor glucine and furfurol oligomer for water mineral suspensions]. Monograph. Belgorod: BSTU publishment. 2012, 108 p. (In Russian).

15. Slusar A.A., Poluektova V.A., Mukhacheva V.D. Beton na osnove vjazhushhego nizkoj vodopotrebnosti i modifikatora SB-FF [Concrete based on binding gent of low water demand and modificator SB-FF]. Stroitel nye materialy [Construction materials]. 2009, № 9, pp. 65-66. (In Russian).

\section{DEAR COLLEAGUES!}

THE REFERENCE TO THIS PAPER hAS THE FOLLOWING CITATION FORMAT:

Shapovalov N.A., Poluektova V.A. Features of nanomodifiers synthesis based on trifunctional oxyphenyls for mineral suspensions. Nanotehnologii v stroitel'stve = Nanotechnologies in Construction. 2016, Vol. 8, no. 5, pp. 100-115. DOI: dx.doi. org/10.15828/2075-8545-2016-8-5-100-115. (In Russian). 
удК 54.057

Автор: ШАПОВАЛОВ Николай Афанасьевич, профессор, д-р техн. наук, первый проректор ФГБОУ ВО «Белгородский государственный технологический университет им. В.Г. Шухова»; ул. Костюкова 46, Белгород, Россия, 308012, val.po@bk.ru;

Автор: ПОЛУэКТОВА Валентина Анатольевна, канд. техн. наук, доц, доцент кафедры теоретической и прикладной химии, ФГБОУ ВО «Белгородский государственный технологический университет им. В.Г. Шухова»; ул. Костюкова 46, Белгород, Россия, 308012 , v.a.poluektova@gmail.com

\section{ОСОБЕННОСТИ СИНТЕЗА НАНОМОДИФИКАТОРОВ НА ОСНОВЕ ТРИФУНКЦИОНАЛЬНЫХ ОКСИФЕНОЛОВ ДЛЯ МИНЕРАЛЬНЫХ СУСПЕНЗИЙ}

\section{АННОТАЦИЯ К СТАТЬЕ (АВТОРСКОЕ РЕЗЮме, РЕФЕРАТ):}

Целенаправленно влиять на реологические свойства высококонцентрированных минеральных суспензий, применяемых в строительной индустрии, позволяет направленный синтез макромолекул наноразмеров и определенного строения, обладающих высокой адсорбционной способностью на поверхности минеральных частиц и способных модифицировать структуру граничного слоя. Адсорбционная способность органических соединений зависит, в первую очередь, от длины углеводородной цепи и молекулярной массы соединения.

В результате конденсационного взаимодействия фенола и его производных с альдегидами получаются олигомеры и полимеры, строение которых зависит от функциональности фенола, вида альдегида, мольного соотношения реагентов, рН среды реакции. Так, меняя тип или функциональность исходных мономеров, либо условия синтеза, можно синтезировать линейные термопластичные олигомеры (новолаки), либо сильно разветвленные термореактивные олигомеры (резолы). Установлено, что получение резолов идет при более мягких условиях в щелочной среде, при этом отсутствует необходимость нейтрализации продуктов реакции, как в случае с получением новолаков, синтез которых, как правило, протекает в кислой среде.

Синтезирован ряд термореактивных олигомеров на основе трифункциональных многоатомных фенолов. Изучены теоретические и практические особенности синтеза резольных олигомеров, определены оптимальные условия синтеза, установлен состав и строение макромолекул методами ИК-, 
ПМР-спектроскопии, жидкостной хроматографии и кондуктометрии, рассчитана длина развернутой олигомерной молекулы. Полученные соединения были отнесены к наноразмерным модификаторам минеральных дисперсий.

Ключевые слова: наномодификатор, трифункциональные фенолы, синтез макромолекул, пластифицирующая способность.

DOI: dx.doi.org/10.15828/2075-8545-2016-8-5-100-115

МАШИНОЧИТАЕМАЯ ИНФОРМАЦИЯ О СС-ЛИЦЕНЗИИ В МЕТАДАННЫХ СТАТЬИ (НTML-КОД):

< a rel="license" href="http://creativecommons.org/licenses/by/4.0/"><img alt="Лицензия Creative Commons" style="border-width:0" src="https://i.creativecommons.org/l/by/4.0/88x31.png" $/></$ a $><$ br $/>$ Произведение «<span xmlns:dct="http://purl.org/dc/terms/" href="http://purl.org/dc/dcmitype/Text" property="dct:title" rel="dct:type"> Особенности синтеза наномодификаторов на основе трифункциональных оксифенолов для минеральных суспензий </span> > созданное автором по имени <a xmlns:cc="http://creativecommons.org/ns\#" href="Нанотехнологии в строительстве. - 2016. - Том 8, № 5. - C. 100-115. - DOI: dx.doi.org/10.15828/2075-8545-2016-8-5-100-115."

property="cc:attributionName" rel="cc:attributionURL"> Шаповалов Н.А., Полуэктова В.А. </а>, публикуется на условиях < rel="license" href="http://creativecommons.org/licenses/by/4.0/">лицензии Creative Commons «Attribution» («Aтрибуция» ) 4.0 Всемирная </a >.<br />Основано на произведении c <a xmlns:dct="http://purl.org/dc/terms/" href="http:// nanobuild.ru/ru_RU/nanobuild-5-2016/" rel="det:source" $>$ http://nanobuild.ru/ru_RU/nanobuild-5-2016/</a $>$. $<$ br $/>$ Pasрешения, выходящие за рамки данной лицензии, могут быть доступны на странице <a xmlns:cc="http://creativecommons. org/ns\#" href="val.po@bk.ru" rel="cc:morePermissions">val.po@bk.ru</a>.

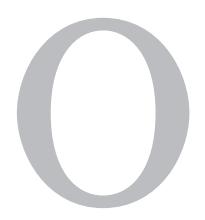

течественные и импортные модификаторы суперпластифицирующего действия для минеральных суспензий, применяемых в строительной индустрии, в большинстве своем представляют синтетические водорастворимые продукты поликонденсации соединений бензольного, нафталинового и полиядерного рядов с альдегидами. Чаще всего продукты конденсации представляют собой смесь олигомеров и полимеров, содержащих молекулы различной степени полимеризации.

Теория адсорбции полимеров на поверхности минеральных частиц разной природы изучена достаточно и наиболее полно представлена в монографии Ю. С. Липатова и Л.М. Сергеевой [1], а также в работах [2-3]. Известно, что адсорбционная способность органических соединений зависит, в первую очередь, от длины углеводородной цепи и молекулярной массы соединения [4-6]. Наиболее активно на гидрофильных поверхностях адсорбируются полимеры с большей молекулярной массой за счет кооперативного эффекта. Адсорбция молекул добавок 
пластифицирующего действия на поверхности твердого тела определяет особенности структуры граничного слоя, это позволяет целенаправленно влиять на реологические свойства высококонцентрированных суспензий, размер агрегатов частиц дисперсной фазы и т.д.

Таким образом, направленный синтез макромолекул наноразмеров и определенного строения, обладающих высокой адсорбционной способностью на поверхности минеральных частиц и способных модифицировать поверхности раздела фаз дисперсных систем для целенаправленного регулирования реологических свойств и агрегативной устойчивости суспензий, является актуальной междисциплинарной задачей.

Известно, что в результате конденсационного взаимодействия фенола и его производных с альдегидами получаются олигомеры и полимеры, строение которых зависит от функциональности фенола, вида альдегида, мольного соотношения реагентов, $\mathrm{pH}$ среды реакции. Так, меняя тип или функциональность исходных мономеров, либо условия синтеза, можно синтезировать линейные (возможны слабо разветвленные) термопластичные олигомеры (новолаки), либо сильно разветвленные термореактивные олигомеры (резолы).

В фенолах реакционноспособными являются атомы водорода, находящиеся в орто- и параположениях к гидроксильной группе. Поэтому одноатомный фенол, двухатомный фенол - резорцин и трехатомный фенол - флороглюцин относятся к трифункциональным оксифенолам. К бифункциональным относятся оксифенолы с гидроксогруппами в орто- или параположениях - пирокатехин и гидрохинон. К монофункциональным следует отнести 1,2,3-тригидроксобензол (пирогаллол).

Реакция поликонденсации моно- и бифункциональных соединений фенола приводит к образованию линейных полимеров, которые растворимы и не отверждаются при нагревании. Моно- и бифункциональные фенолы образуют только термопластичные олигомеры.

Реакцией конденсации с трифункциональными фенолами (фенол, м-крезол и 3,5-ксиленол, резорцин, флороглюцин) можно получить пространственные - сначала образуются плавкие и растворимые термореактивные олигомеры, которые при нагревании способны переходить в нерастворимые неплавкие полимерные молекулы с пространственным строением.

Из альдегидов лишь формальдегид и фурфурол способны образовывать термореактивные олигомеры при поликонденсации с трифункци- 
ональными фенолами. Другие альдегиды (уксусный, масляный и т. д.) вследствие пониженной химической активности и пространственных затруднений не образуют термореактивных олигомеров.

В БГТУ им. В.Г. Шухова за последние двадцать лет получены добавки на основе:

1) фенолформальдегидных олигомеров: СБ-Ф - на основе чистого фенола; СБ-А, СБ-2А - на основе отходов производства фенола, отличающихся строением олигомеров вследствие различной последовательности стадий сульфирования и поликонденсации [7];

2) резорцинформальдегидных олигомеров: СБ-Р и СБ-3 - на основе чистого резорцина и отходов его производства соответственно, в качестве конденсирующего агента использовали формалин [7-10];

3) резорцинфурфурольных олигомеров: СБ-РФ и СБ-5 - на основе чистого резорцина и отходов его производства соответственно, в качестве конденсирующего агента использовали фурфурол $[11,12]$.

4) флороглюцинфурфурольных олигомеров: СБ-ФФ - на основе чистого флороглюцина, в качестве конденсирующего агента использовали фурфурол [13-15].

Исследования показали, что при поликонденсации оксифенолов с формальдегидом могут быть синтезированы как термопластичные, так и термореактивные олигомеры.

Термопластичные (новолачные) олигомеры образуются в следующих случаях:

- при соотношение фенол : формальдегид 1:0,78-0,86 (избыток фенола) в кислой среде;

- при соотношение фенол : формальдегид 1:2-2,5 (большой избыток формальдегида в присутствии кислотных катализаторов (сильнокислая среда).

Термореактивные (резольные) олигомеры образуются в следующих случаях:

- при поликонденсации трифункционального фенола, взятого в избытке, с формальдегидом в щелочной среде (основные катализаторы). При этом следует отметить, что резольные олигомеры получаются даже при многократном избытке фенола, который остается в продуктах реакции в растворенном виде;

- при количестве формальдегида, взятого в небольшом избытке как в кислой, так и в щелочной средах. 
Таким образом, получение термопластичных олигомеров, как правило, возможно в присутствии кислотных катализаторов, что вызывает необходимость нейтрализации продуктов реакции, для использования их в качестве суперпластифицирующих добавок. Синтез термореактивных олигомеров протекает при более мягких условиях в присутствии основных катализаторов.

В ходе данной работы был синтезирован ряд термореактивных олигомеров (резолов) на основе трифункциональных фенолов. В качестве мономеров для синтеза использовали многоатомные фенолы: резорцин или флороглюцин, обладающие большой реакционной способностью по сравнению с фенолом вследствие суммарного влияния двух (трёх) гидроксильных групп. В качестве конденсирующего агента использовали как широко применяемый для синтеза пластифицирующих добавок формальдегид, так и фурфурол. Для получения термореактивных олигомеров синтез вели в присутствии щелочных катализаторов.

\section{Получение резорцинформальдегидного наномодификатора}

Схема поликонденсации резорцина с формальдегидом в щелочной среде может быть представлена следующим образом:

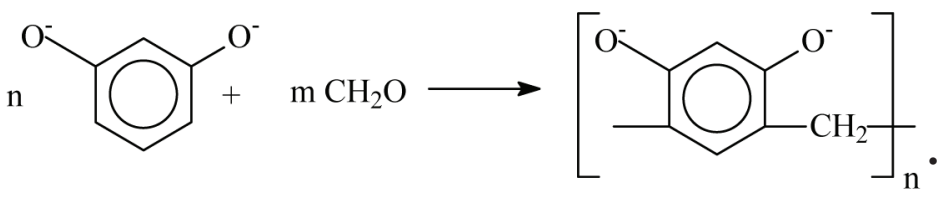

В результате реакции получали термореактивные олигомеры различной средней молекулярной массы, состав и строение которых определялся соотношением исходных реагентов, их концентрациями и температурой. Изменение температуры значительно влияло на скорость реакции.

Анализ результатов показал, что оптимальным отношением реагентов для получения резорцинформальдегидных резолов с наибольшей пластифицирующей способностью является мольное соотношение компонентов формальдегид/резорцин 0,82 .

Кинетику получения олигомеров исследовали с помощью жидкостной хроматографии на хроматографе Х尔-1305. В качестве адсорбента 
использовали «ДАУЭКС-Н» фракции 100-150 мкм. Длина колонки 15 см, диаметр 0,1 см, элюент - бидистиллированная вода, скорость потока - 0,125 $\mathrm{cm}^{3} /$ час; анализ проводили на длине волны 275 нм, соответствующей максимуму поглощения соединений. Время выхода для жидкостной колоночной хроматографии определялось наличием тех или других функциональных групп. Смесь метилольных производных и олигомеров, имеющих разную молекулярную массу, но одинаковые функциональные группы, выходили одним пиком. В соответствии с этим на хроматограмме наблюдалось два пика, первый из которых соответствует сумме метилольных производных и олигомерных продуктов, второй - резорцину.

Изучение зависимости концентрации резорцина и продуктов конденсации от времени синтеза при оптимальном мольном соотношении реагентов показало, что концентрация резорцина резко уменьшается и через 5-7 мин достигает практически постоянной величины, составляющей не более $5-8 \%$ от исходной величины. Это объясняется тем, что резорцин расходуется в быстрой реакции образования метилольных производных, в то время как лимитирующей стадией процесса является реакция взаимодействия метилольных соединений друг с другом с образованием молекул олигомеров. Лимитирующая роль реакции образования олигомеров подтверждается также зависимостью молекулярной массы продуктов поликонденсации от времени синтеза. В то время как весовая концентрация продуктов реакции после 5 минут синтеза остается постоянной, молекулярная масса продолжает увеличиваться, и только через 40-50 минут ее рост замедляется.

Одновременное определение пластифицирующей способности продуктов реакции показало, что вначале молекулярная масса и пластифицирующая способность увеличиваются симбатно, но, начиная с молекулярной массы 750-800, дальнейшее ее возрастание не приводит к росту пластифицирующей способности. Это свидетельствует о том, что увеличение длины цепи олигомерных молекул оказывает влияние на пластифицирующую способность только до определенного предела. При мольном соотношении реагентов около 0,98 образуется высокомолекулярный полимер, нерастворимый в воде. Таким образом, оптимальными условиями синтеза являются: мольное соотношение формальдегид/резорцин 0,82 , температура $70^{\circ} \mathrm{C}$, время синтеза $40 \mathrm{мин,} \mathrm{загрузка}$ катализатора - 5\% от массы резорцина. 
При изучении состава и строения модификатора на основе резорцинформальдегидных резолов использовали образец со среднечисловой молекулярной массой $750 \pm 10$.

Сравнение УФ-спектров резорцинформальдегидных резолов и резорцина показало, что характер спектра изменился. Сдвиг полосы поглощения в области 28000-36000 $\mathrm{cm}^{-1}$ свидетельствует о том, что степень сопряжения в ароматических кольцах олигомерных молекул увеличилась.

Сравнительный анализ ИК-спектров резорцинформальдегидных резолов и резорцина показал, что характерными в обоих случаях являются следующие полосы поглощения: $1608 \mathrm{~cm}^{-1}, 1500$ (валентные колебания $\mathrm{C}=\mathrm{C}$ кольца), 1370 (валентные колебания $\mathrm{C}-\mathrm{O}$ фенола), 1295 (колебания ароматического цикла), 1165 (плоскостные деформационные колебания фенольных ОН-групп). Для резорцина наблюдались также полосы поглощения, характерные для 1,3 - замещения: в области 1900-2000 $\mathrm{cm}^{-1}$, а также 850, 773, $680 \mathrm{~cm}^{-1}$. В случае олигомеров эти полосы поглощения исчезают и появляются новые: 1450 (деформационные колебания $\mathrm{C}-\mathrm{H}$ в $\mathrm{CH}_{2}$-группе), 1227 (деформационные колебания $\mathrm{OH}$ в первичных спиртах), 1085 (валентные колебания C-O в первичных спиртах), 900 (внеплоскостные деформационные колебания $\mathrm{C}-\mathrm{H}$ в 1,2,4 и 1,2,4,5-замещенных бензола), 840 (внеплоскостные деформационные колебания СН в 1,2,4-замещенных бензола).

Сравнение ПМР-спектров резорцинформальдегидных олигомеров и резорцина показало, что в спектрах олигомеров наблюдается снижение мультиплетности и уменьшение интенсивности сигнала в области 6-7 м.д., обусловленное уменьшением количества протонов в ароматическом кольце. В спектре резольных олигомеров появляется сигнал в области 3,6 м.д., соответствующий $\mathrm{CH}_{2}$-протонам, связанным с ароматическим кольцом. Изменяется также интенсивность сигнала в области 8 м.д., обусловленного протонами ОН-групп.

В молекуле резорцинформальдегидного модификатора кондуктометрическим методом обратного титрования определили количество фенольных гидроксильных групп. Расчет проводили по формуле

$$
n_{\phi е н}=\frac{\left(V_{2}-V_{1}\right) \cdot N \cdot M}{C_{о л} \cdot V_{о л}} \text {, }
$$


где $n_{\text {фен }}$ - количество фенольных ОН-групп в молекуле олигомера; $V_{1}$ - объем $\mathrm{HCl}$, пошедший на титрование избытка щелочи; $V_{2}-$ суммарный объем HC1, пошедший на титрование щелочного раствора олигомера; $N$ - нормальность $\mathrm{HC} 1 ; M-$ молекулярная масса олигомера; $C_{\text {ол }}$ концентрация олигомеров, кг/м²3

Расчет показал, что количество ОН-групп на одну молекулу составляет 10,07, при этом в повторяющемся структурном звене молекулы резола остаются неизменными по сравнению с резорцином. Это является прямым доказательством того, что фенольные ОН-группы не участвуют в реакции поликонденсации. Таким образом, строение молекул резорцинформальдегидного модификатора можно представить в виде следующей модели (рис. 1).

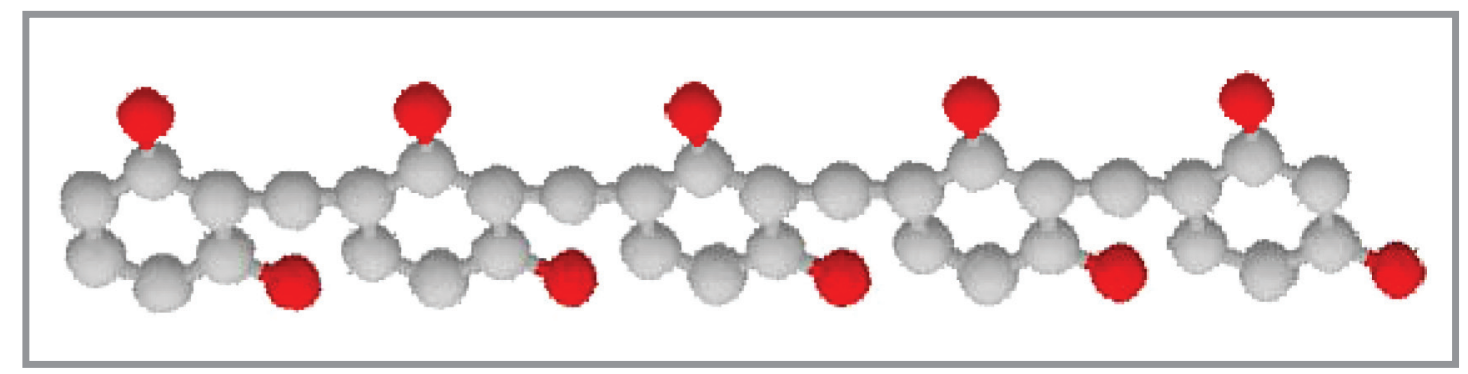

Рuc. 1. Модель строения молекул резорцинформальдегидного модификатора

Используя значения атомных радиусов либо длин связи, получаемых суммированием атомных радиусов, была рассчитана длина предполагаемой развернутой молекулы резорцинформальдегидного модификатора. Известно, что все связи $\mathrm{C}-\mathrm{C}$ в бензольном кольце равноценны, их длина равна 0,140 нм, что соответствует промежуточному значению между длиной простой связи $(0,154$ нм) и двойной $(0,134$ нм $)$. Исходя из этого, размер молекулы бензола принято считать около 0,5 нм. Длина связи С-O равна 0,126 нм. Атомные радиусы углерода и кислорода равны соответственно 0,077 и 0,066 нм:

$$
L=(0,5+0,126+0,066) \cdot 5+0,154 \cdot 2 \cdot 4=4,7 \mathrm{HM} .
$$

Таким образом, на основе резорцинформальдегидных олигомеров был получен модификатор, молекулы которого имеют наноразмеры. 


\section{Получение флороглюцинфурфурольного наномодификатора}

Схему протекания поликонденсации флороглюцина с фурфуролом в щелочной среде можно представить следующим образом:<smiles>[O-]c1cc([O-])cc([O-])c1</smiles><smiles>Cc1c([O-])cc([O-])c(C(C)C)c1C(C)C=O</smiles>

Синтез флороглюцинфурфурольных резолов исследовали с помощью ПМР-спектрометра «TESLA BS-476A» с термозондом с рабочей частотой 60 МГц и жидкостного хроматографа с DIFFERENTAL REFRACTOMETER RIDK 101. В качестве адсорбента использовали «SEPARON SC-X C-18», элюентом служила бидистиллированная вода.

Была изучена зависимость концентрации флороглюцина и фурфурола от времени синтеза при оптимальном мольном соотношении реагентов. На дифференциальном ПМР-спектре механической смеси фурфурола с флороглюцином в области 9-10 м.д. имеется пик, образованный в результате резонанса альдегидных протонов фурфурола (рис. 2).
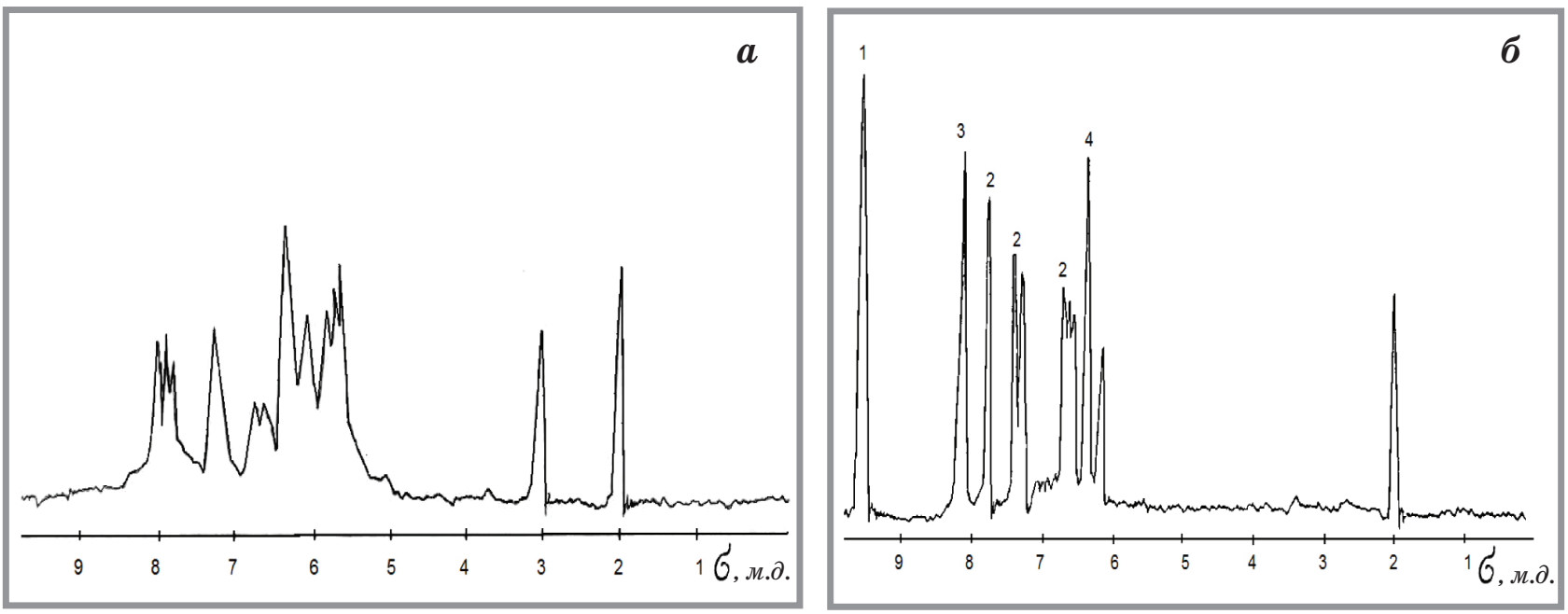

Рис. 2. ПМР-спектры: а - смеси флороглюцина и фурфурола;

б - флороглюцинфурфурольного резола в дейтероацетоне:

1 - протоны альдегидной группы фурфурола; 2 - протоны фуранового кольца; 3- протоны ОН- групп флороглюцина; 4 - ароматические протоны флороглюцина 
В ходе реакции поликонденсации путем снятия интегральных кривых определяли зависимость площади этого пика от времени реакции. Изменение площади соответствует изменению относительной концентрации альдегидного протона в реакционной смеси. В результате реакции этот пик постепенно исчезал, но появлялся новый пик в области 3 м.д., что свидетельствует о возможном образовании - СН-групп (рис. 2). Уширение сигналов ароматических протонов свидетельствовало о связи молекул в олигомеры и снижении степени подвижности данных протонов. В области 8 м.д. сохранялся сигнал, соответствующий протонам ОН-групп флороглюцина, т.е. фенольные группы не участвуют в синтезе, однако наблюдалось расщепление данного сигнала, что соответствует изменению влияния соседних протонов в результате появления дополнительных заместителей в ароматических кольцах флороглюцина.

Строение флороглюцинфурфурольных резолов определяли с помощью ИК-спектроскопии на ИК-Фурье-спектрометре Vertex 70, ПМРспектроскопии и жидкостной хроматографии. Из соотнесения полос поглощения на ИК-спектре сделан вывод, что в спектре СБ-ФФ сохраняются полосы в области $1610 \pm 5 \mathrm{~cm}^{-1}, 1500 \pm 10 \mathrm{~cm}^{-1}$ (валентные колебания $\mathrm{C}=\mathrm{C}$ ароматического кольца), $1370 \pm 10 \mathrm{~cm}^{-1}$ (валентные колебания C-O фенольные), $1165 \pm 10 \mathrm{~cm}^{-1}$ (плоскостные деформационные колебания фенольных ОН-групп), $1075 \pm 10 \mathrm{~cm}^{-1}$ (валентные колебания $\mathrm{C}-\mathrm{O}-\mathrm{C}$ фуранового кольца), а полосы в области $1680 \pm 5 \mathrm{~cm}^{-1}$ (валентные колебания $\mathrm{C}=\mathrm{O}$-карбонильные) исчезают. Появляется интенсивный пик в области $3450 \pm 10 \mathrm{~cm}^{-1}$ (валентные колебания атомов водорода групп $\mathrm{C}-\mathrm{H}$ ).

Данные, полученные с помощью хроматографического анализа, показали, что в начале реакции совместной конденсации флороглюцина с фурфуролом образуются их монопроизводные соединения. Вследствие своей высокой растворимости на хроматограмме они выходят раньше других компонентов реакционной смеси. С течением времени наблюдается снижение интенсивности пика флороглюцина и практически полное исчезновение пика фурфурола. Через 40-50 мин происходит дальнейшее изменение структуры молекул, о чем свидетельствует уменьшение пика монопроизводных и пика оставшегося флороглюцина и появление пика олигомеров. Результаты, полученные на ПМРспектрометре и жидкостном хроматографе, достаточно хорошо соответствуют друг другу. 
Таким образом, на основании данных ИК-спектороскопии, ПМРспектроскопии, жидкостной хроматографии, кондуктометрического титрования (расчет показал, что, в среднем, в одной молекуле содер-

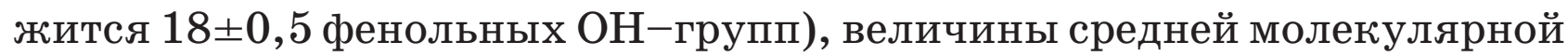
массы при оптимальных условиях синтеза, равной $950 \pm 10$, строение молекул флороглюцинфурфурольного модификатора можно представить в виде следующей модели, представленной на рис. 3.

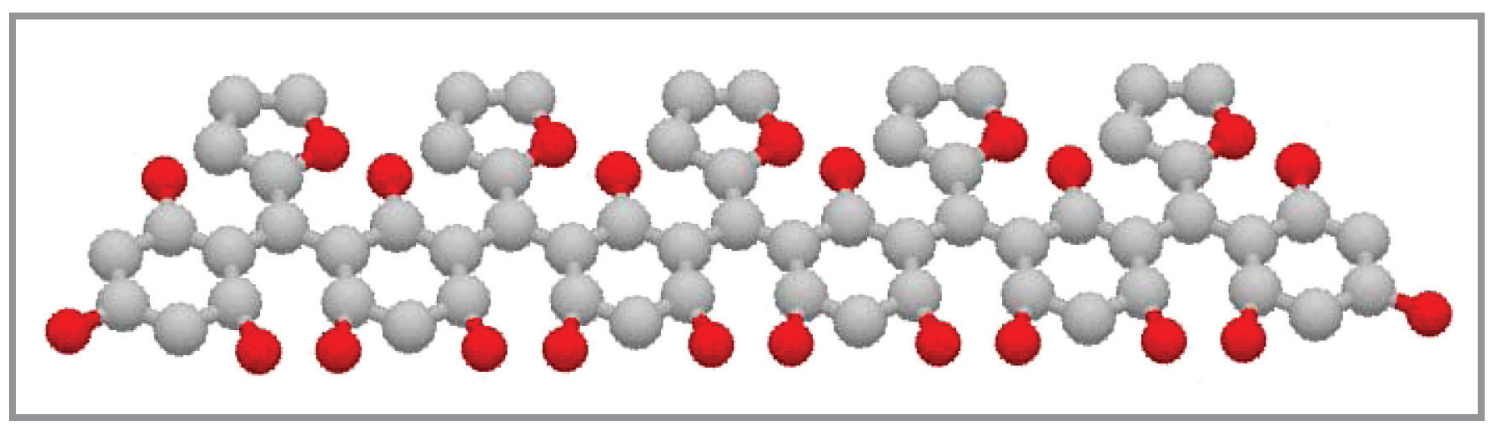

Рuc. 3. Модель строения молекул флороглюцинфурфурольного модификатора

Используя значения атомных радиусов и длин связи, была рассчитана длина предполагаемой развернутой молекулы флороглюцинфурфурольного модификатора :

$$
L=(0,5+0,126 \cdot 2+0,066 \cdot 2) \cdot 6+0,154 \cdot 2 \cdot 5=6,8 \mathrm{Hм} .
$$

Исходя из полученного значения, модификатор на основе флороглюцинфурфурольных олигомеров также можно отнести к наномодификаторам. При этом необходимо отметить, что флороглюцинфурфурольные резолы обладают бо́льшей пластифицирующей способностью в минеральных суспензиях по сравнению с резорцинформальдегидными олигомерами, что, по нашему мнению, обусловлено большим количеством оксигрупп в молекулах, которые участвуют в адсорбционных процессах.

Таким образом, в ходе данной работы установлено, что получение термореактивных олигомеров идет при более мягких условиях в щелочной среде, при этом отсутствует необходимость нейтрализации продуктов реакции, как в случае с получением термопластичных олигомеров, синтез которых, как правило, протекает в кислой среде. 
Изучение теоретических и практических особенностей синтеза резольных олигомеров, определение оптимальных условий синтеза, установление состава и строения термореактивных олигомеров на основе трифункциональных многоатомных фенолов методами ИК-, ПМР-спектроскопии, хроматографии, кондуктометрии и др., расчет максимальной длины развернутой олигомерной молекулы позволили получить соединения, которые можно отнести к наномодификаторам минеральных дисперсий.

Работа выполнена в ралках научного проекта № 14-41-08015 p_офи_л при финансовой поддерже РФФИ и Правительства Белгородской области.

УВАЖАЕМЫЕ КОЛЛЕГИ!

ПРИ ИСПОЛЬЗОВАНИИ МАТЕРИАЛА ДАННОЙ СТАТЬИ

ПРОСИМ ДЕЛАТЬ БИБЛИОГРАФИЧЕСКУЮ ССЫЛКУ НА НЕЁ:

Шаповалов Н.А., Полуэктова В.А. Особенности синтеза наномодификаторов на основе трифункциональных оксифенолов для минеральных суспензий // Нанотехнологии в строительстве. - 2016. - Том 8, № 5. - С. 100-115. - DOI: dx.doi.org/10.15828/2075-8545-2016-8-5-100-115.

\section{Dear colleagues!}

THE REFERENCE TO THIS PAPER HAS THE FOLLOWING CITATION FORMAT:

Shapovalov N.A., Poluektova V.A. Features of nanomodifiers synthesis based on trifunctional oxyphenyls for mineral suspensions. Nanotehnologii $\mathrm{v}$ stroitel'stve $=$ Nanotechnologies in Construction. 2016, Vol. 8, no. 5, pp. 100-115. DOI: dx.doi. org/10.15828/2075-8545-2016-8-5-100-115. (In Russian). 


\section{Библиографический список:}

1. Липатов Ю.С., Сергеева Л.М. Адсорбция полимеров. - Киев: Наукова думка, 1972. $196 \mathrm{c.}$

2. Липатов Ю.С. Современные теории адсорбции полимеров на твердых поверхностях // Успехи химии. - 1981. - Том 50, № 2. - С. 355-379.

3. Харитонова Т.В., Иванова Н.И., Сушм Б.Д. Адсорбция катионного и неионогенного ПАВ на поверхности $\mathrm{SiO}_{2}$ из водных растворов / / Коллоидный журнал. - 2005. - Т. 67, № 2. - C. 274-280.

4. Полуэктова В.А., Шаповалов Н.А., Балятинская Л.Н. Адсорбция оксифенолфурфурольных олигомеров на дисперсных материалах // Фундаментальные исследования. - 2012. - № 11. Ч. 6. - С. 1470-1474.

5. Вовк А.И. Анализ взаимосвязи строения ПАВ с их адсорбционными характеристиками в системе цементный минерал - вода // Коллоидный журнал. - 1997. - Т. 59, № 6. - С. 743-746.

6. Долинный А.И. Адсорбция из смеси полимеров. Эффект молекулярной массы // Коллоидный журнал. - 2006. - Т. 68, № 1. - С. 37-45.

7. Шаповалов H.A. Регулирование агрегативной устойчивости минеральных суспензий олигомерными ароматическими электролитами: автореферат ... д-ра техн. наук. Белгород, 1999. - $32 \mathrm{c.}$

8. Полуэктова В.А., Ломаченко В.А., Столярова З.В., Ломаченко С.М., Малиновкер В.М. Коллоидно-химические свойства водных дисперсий мела и мрамора // Фундаментальные исследования. - 2014. - № 9. Ч. 6. - С. 1205-1209.

9. Poluektova V.A., Stolyarova Z.V., Lomachenko S.M., Chernikov R.O. Adsorption of domestic wastes-based modifier of resorcinol on the surface of mineral particles // Міжнародний науковий журнал. - 2015. - № 4. - С. 45-46.

10. Poluektova V.A., Shapovalov N.A., Kosukhin M.M., Slusar A.A. Plasticizing Additives For Water Mineral Dispersions On The Basis Of Oxyphenol Oligomers // Advances in Natural and Applied Sciences. - 2014. - Vol. 8, № 5. - C. 373-379.

11. Слюсарь А.А., Шаповалов Н.А., Полуэктова В.А. Регулирование реологических свойств цементных смесей и бетонов добавками на основе оксифенолфурфурольных олигомеров // Строительные материалы. - 2008. - № 7. - С. 42-43.

12. Слюсарь A.А., Полуэктова В.А., Мухачева В.Д. Коллоидно-химические аспекты пластификации минеральных суспензий оксифенолфурфурольными олигомерами // Вестник БГТУ им. В.Г. Шухова. - 2008. - № 2. - С. 66-69.

13. Poluektova V.A., Shapovalov N.A., Gorodov A.I. Modifiers On The Base Of Oxyphenol Chemical Production Waste For The Industrial Mineral Suspensions // International journal of applied engineering research. - 2015. - Vol. 10, № 21. - C. 42654-42657.

14. Полуэктова В.А., Слюсарь А.А., Шаповалов Н.А. Суперпластификатор на основе флороглюцинфурфурольных олигомеров для водных минеральных суспензий: монография. - Белгород: Изд-во БГТУ, 2012. - 108 с.

15. Слюсарь А.А., Полуэктова В.А., Мухачева В.Д. Бетон на основе вяжущего низкой водопотребности и модификатора СБ-ФФ // Строительные материалы. - 2009. - № 9. C. 65-66. 